\title{
Using images as a stimulus to explore the identity of student teachers in computing
}

\author{
Eleanor Overland \\ Faculty of Education, Manchester Metropolitan University, Manchester, UK \\ e.overland@mmu.ac.uk
}

\begin{abstract}
The computing curriculum in English secondary education is now officially in its second year of implementation. A new, specialist group of student teachers are being trained to be able to deliver the new, rigorous computing curriculum. In this emerging curriculum area, it is essential teachers explore their own identity, beliefs and values in order to deliver effectively and ensure enjoyment for both themselves and the pupils they teach. In this study, the student teachers engage with images and place them in a hierarchy to stimulate honest discussion and exploration of computing teacher identity. Whilst the student teachers resonate with approaches in the classroom, such as group work, engagement with the computing curriculum topics themselves are limited and show an area which may require more attention and challenge in the computing teacher training programme.
\end{abstract}

Keywords: Computing education, ICT education, student teachers, ITE, images, diamond 9, teacher identity.

\section{$1 \quad$ Introduction}

The National Curriculum in England has undergone a significant shift; from September 2014 ICT education was withdrawn and replaced with computing [6]. As a result, Initial Teacher Education (ITE) courses have been updated to reflect the requirement for new, specialist teachers to enter the profession. Secondary trainee teachers in England now follow courses in 'Computing' or 'Computing with [Information and Communication Technologies] ICT'. The courses attract a range of graduate applicants, some direct from computing-related degree courses and others from industry and computer-related employment. For some applicants their computing subject knowledge is broad and in sufficient depth to teach to the highest levels, others may have more specialist backgrounds and so need to follow a computing subject knowledge enhancement course prior to teacher training. The opportunity to teach the 'new' subject attracted 878 students in England between 2013 and 2015 [5]. The availability of bursaries to support career change and the availability of subject knowledge enhancement courses has brought in a wide range of students, differing in age, background and expectations. Added to the eclectic mix of students are a range of school-based mentors, many of whom are not computing specialists themselves but may have been teaching an ICTbased curriculum for considerable time. Those that are computing specialists may have 
found themselves teaching mathematics or more science-based subjects so the opportunity to engage with their specialism is also a new experience. Although a rapidly developing area, finding trainee teachers an experienced school-based mentor who is a computing specialist is a challenge.

The context of change and curriculum reform adds an additional layer of complexity for trainee computing teachers. Developing an identity as a teacher, whilst a changeable and evolving process, is crucial as part of any ITE where students are given the opportunity to explore their values and beliefs, how they are learning and the context in which they will work; a process of becoming [1]. The computing trainees may well receive mixed messages from mentors, university tutors, the media and pupils themselves. All those involved in the curriculum change will also be identifying their own role and position within it so therefore, whilst thinking primarily of their own position, the trainees are also subject to mixed rhetoric from those around them. Exploring identity within this context is therefore more crucial yet more challenging than for many other subject areas at this time.

\section{$2 \quad$ Exploring identity}

\subsection{The importance of identity construction}

Studies have found supporting teachers in the exploration of their identity has allowed teachers to 'grow in service to students', develop better teaching, renew practice and ultimately enjoy the role $[8,10]$. Leuhmann prioritised 'recognition work' with student science teachers in order to provide opportunities for the student teachers to explore their identity through personal reflection and exploratory processes such as keeping journals and engaging in discussion. The methods of exploring teacher identity vary in nature but are similar in aim, in order to identify external influences (including prior experience and own education), professional factors, personal factors and uncovering a set of values, beliefs and goals held by the teacher [12].

$\mathrm{Ni}$ and Guzdial [12] carried out a study exclusively with teachers of computer science in the United States of America (USA). They found varied identities, with particular differences in motivation and confidence with the subject of computer science. Respondents in the survey very much attached themselves to labels such as programming, computer science and the complexities of the subject. With the current government rhetoric in England there is a danger of current student teachers in computing finding themselves attached to the lexicon rather than the underlying values and priorities they have as computing teachers. There is a drive for computing to portray itself as having far more academic rigour and challenge than its predecessor, ICT, and current student teachers are very much part of this emerging landscape [14].

Assessment practices are also developing. The national qualifications in England taken by school pupils at age 16 years now require $80 \%$ of assessment to be completed through written examinations. This results in very little of the two-year course being practical requiring 'project based' computing solutions. For student teachers this may be at odds with their own experience in industry before training to be teachers or in their own personal experience of being engaged in the 'maker movement' or 'hackerthon' 
type events. In these, constructivism is very much favoured with participants 'playing' and exploring to discover new learning [9].

Support during the teacher training course and in negotiating a path through the range of conflicting influences, terminology and rhetoric is provided by school-based mentors. School-based mentors help shape the teacher the student becomes through the communication of classroom practice-based values that the student may then receive or reject. At the same time, the students will need to feel valued by their mentors in order to feel self-worth in their development as teachers [17]. Where the student teachers may have greater subject knowledge than their mentors this may add complexity to how mentors support the development of student teacher identity. Subject knowledge may become less of a priority for the students or could even lead to them devaluing the beliefs and advice of the mentors and so seek values from alternative sources.

\subsection{Image as a provocation}

In an attempt to break away from the lexicon of the emerging computing curriculum, a visual approach to exploring identity is being taken. The theoretical frameworks for this study are varied yet interwoven. The study draws on identity theory and on semiology; how is identity portrayed or interpreted? The study also 'borrows' from art theorists. This section outlines the frameworks that are drawn upon in this study but also explores the overlaps within the fields.

Foucault considers a painting of a pipe, which features a blackboard stating 'this is not a pipe' within the image, depicting yet another pipe. The reading of this image by Foucault outlines a number of ambiguities [7]. The discussion extends for some time and raises a number of questions about the painting. What is clearly illustrated is the non-relation, or the very complex relation between the painting and its title. The intention of the artist, Magritte, is to challenge the viewer of the image and focus their attention on the very act of naming. The tension between the naming of the painting and the objects portrayed, resemblance and affirmation, is where the viewers (or 'reader' of the image) are forced to think, to devise meaning and consider their own view. Without the text, the painting would be accepted by most as a representation of a pipe.

The tension that can be created through visual representation and opposing text can also be initiated through contradictory images. In an attempt to move away from lexicon, the same tensions can be developed and so similar commitment from the 'reader' is required. Two images are presented, using the anchorage 'pupils at work'; firstly an image of children sitting in rows, working on paper without evident speech or movement; secondly, a small group of children clearly talking and focussed on a central resource. A choice needs to be made, which one is most representative of 'pupils at work'. For this to happen, as a reader of the images, you would need to draw on your own experiences, your understanding of 'work' and which image most resonates. The comparative process aids the reader, not only to view the image, but consider their own position and so new understanding of it.

There is a concern that this process of comparing and selecting images is simplistic and limited in scope. The images may be isotopic in nature so the comparison becomes superficial, a tangle of words and images with little contradiction to sustain a purposeful discourse $[7,11]$. However, within this process of comparing images, the multiplicity 
of layers and 'readings' on an image adds further value and legitimacy to the method. Even the most naive of images (produced without intention or message, if this is indeed possible) will convey characteristics of a message; even if not substantial these will be relational in some way to the 'reader' [2]. Without applying their own experience and prior understanding to the reading, signs would not be understood and the image would be unintelligible to the reader. Each reading of an image is therefore individual, based on experience and understanding, so in exploring one's own readings of signs, a consideration of one's own experience, beliefs and identity will be required.

\section{$3 \quad$ Methodology}

The study involved 40 trainee computing teachers from two different cohorts between September 2014 and December 2015. The students worked in pairs to discuss, respond and reflect on the process.

\subsection{The images}

Participants were given 18 images and requested to select only 9 to feature in their completed diagram. This first part of the process required the trainee teachers to act as 'readers' of the images. They discussed what each of the images meant to them and agreed half of the images to be discarded. They were instructed to keep the 9 that most resonated with them as teachers of computing. By working in pairs, the students were required to articulate their view of each image and come to a consensus as to which images are given priority.

The images selected for the process were varied in nature and included a selection of photographs from classroom situations, topics delivered within ICT or computing classrooms, and pupil work. Each image was numbered for purposes of analysis but these were allocated randomly. The students were given the images as a shuffled pile of cards. The students were given no further information on what the images depicted, although they were much larger than the examples presented below. Students were asked to annotate, wherever appropriate, to provide an insight into their reading or positioning of the image. A copy of all images is available online [18]. 


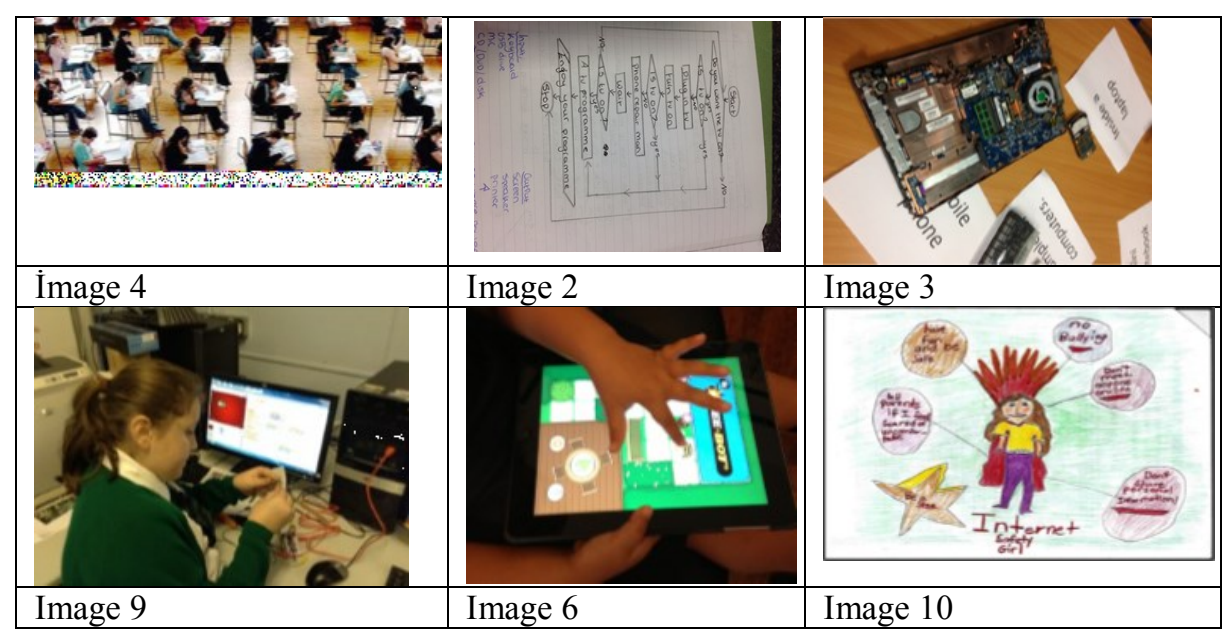

Figure 1: Examples of images from the study

Depicting pupil activity within learning settings (Figure 1):

- Image 4 is a view of a typical examination setting. All English national computing qualifications will require $80 \%$ assessment through a written examination.

- Image 9 is a pupil connecting a MakeyMakey with Scratch running on screen.

Depicting pupil work in computing or ICT lessons:

- Image 2 shows a hand-drawn flow chart.

- Image 6 shows a pupil working on a tablet, in this case using the Beebot application.

Depicting classroom display or on-screen presentation of pupil work from computing and ICT lessons:

- Image 3 shows two separate pieces of hardware along with moveable printed labels.

- Image 10 is a hand-drawn poster depicting 'Internet Safety Girl'.

Following the discussion and selection of an agreed 9 images, the students were given a 'Diamond 9' shape as shown in Figure 2. They were requested to place their images within the hierarchical structure, the most important being at the top of the diamond and the least at the base. This time, rather than just being 'readers' of images, the students were required to draw on their beliefs, values and classroom practice to prioritise images. This process has been used successfully to develop discussion and identify tacit thoughts of abstract concepts, particularly with school age children [3, 13]. 


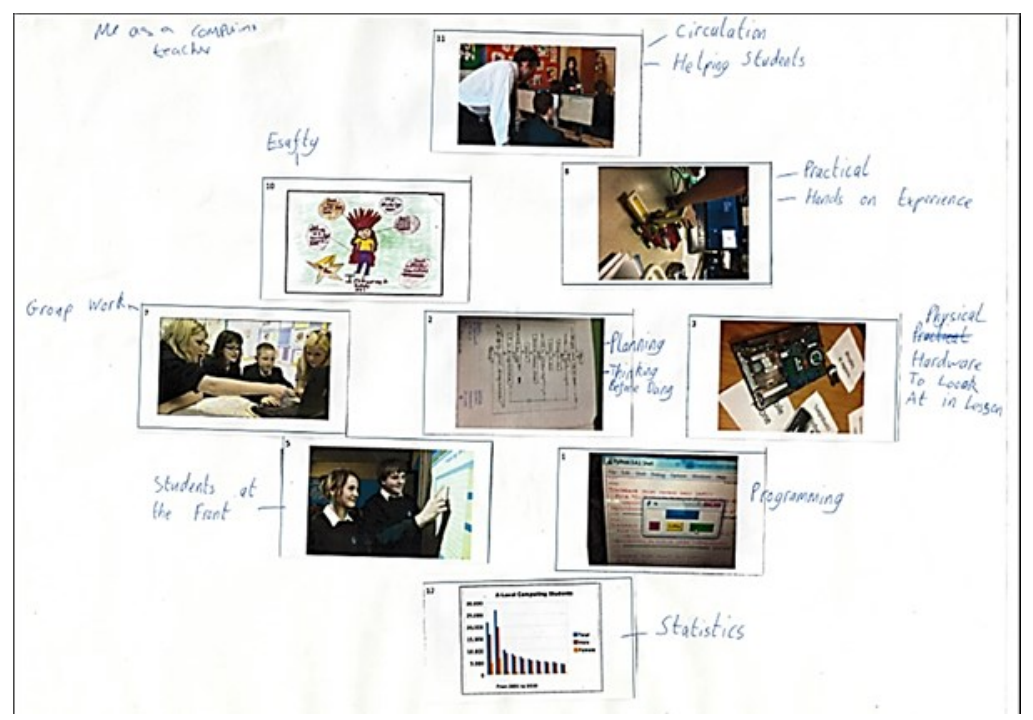

Figure 2: An example of a completed Diamond 9

\section{$4 \quad$ Results and findings}

Approaches to analysis of the data are three-fold. The first two make use of a basic statistical analysis to identify patterns and trends in the selection and placement of the data. The first looks at the overall usage of each image using a weighted score dependent on the position anywhere within the Diamond (Figure 3).

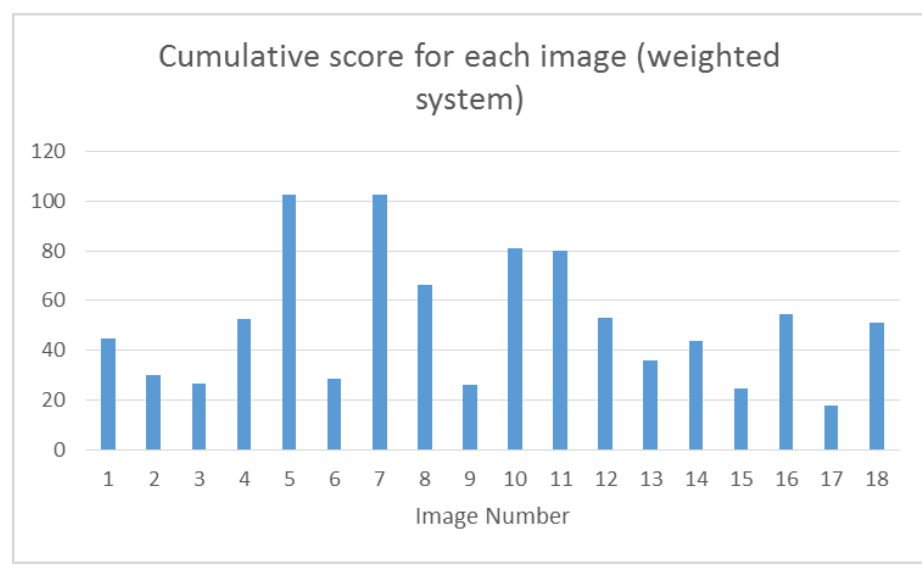

Figure 3: Summary data showing weighted scores for each image based on overall use within the Diamond 9 
The second simply identifies the images most commonly used in the top 3 rows of the diamond formation (Figure 4). Thirdly the Diamond 9 responses are compared to consider the annotation added by the participants.

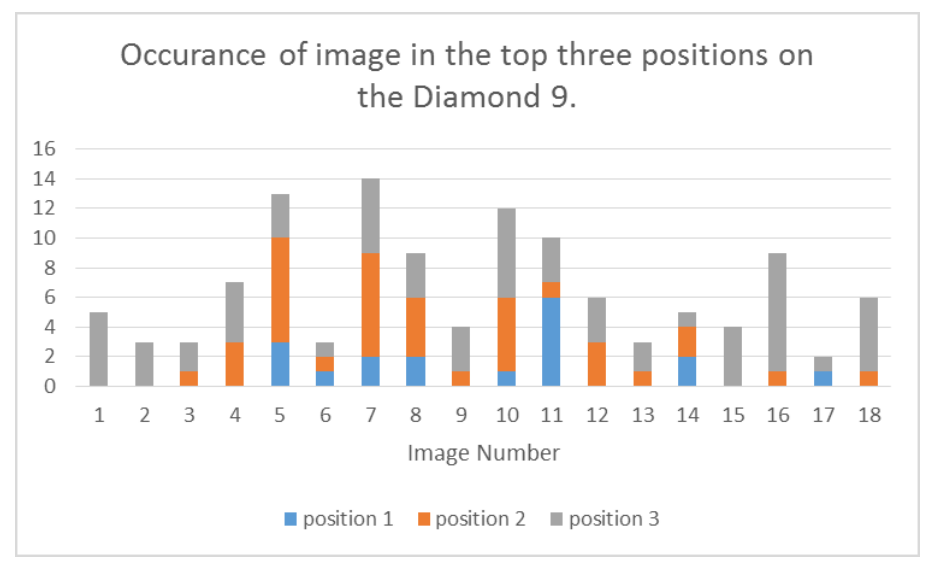

Figure 4: Summary data showing frequency of images used in the top three positions within the Diamond 9

Images 5 and 7 are most prevalent in their use within the diamonds. One depicts pupils clearly conversing and working together around a laptop. It is labelled throughout the responses with appropriate 'buzz words' (for example, Figure 5). These are terms that currently feature prominently across much teacher training and development across all curriculum areas. These descriptors include 'peer learning', 'group work', 'interactive learning', 'learning by doing', 'active learning' and 'experimental learning'. Also featuring highly are practical work, pupil-led learning and teacher support.

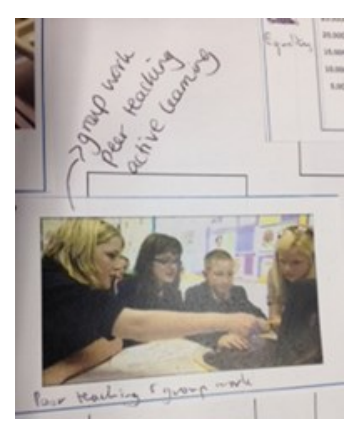

Figure 5: Annotated image 7 labelled as group work, peer teaching and active learning

Image 10 also featured strongly throughout many of the diamonds. Interestingly, it is one of the few images that does not depict a computer or some aspect of specific computing subject knowledge. The image portrays a hand-drawn 'super hero girl' who knows how to stay safe online. The annotations (Figure 6) mainly feature an 'e-safety' 
label, never alluding to a reading of the image other than the safety message. The trainees are reading this image as the pupil illustrator intended and have held fast to the message. They have identified safeguarding as being one of their top-most priorities as a teacher, the need to protect and even nurture the pupils in their use of the internet. This notion of the caring nature of the role resonates strongly with some of the findings Walkerdine identified from her own exploration of teacher identity [16].

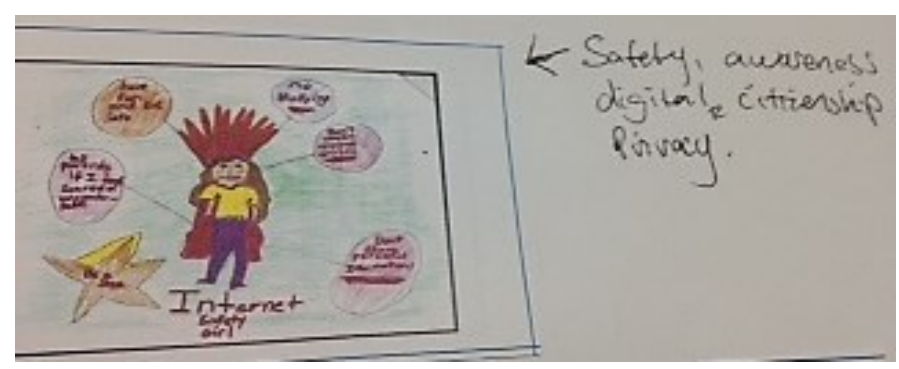

Figure 6: Annotated Internet Safety Girl

Interestingly, code, assessment and curriculum seldom featured or were placed in low positions on the Diamond. Where they were included the annotation was very basic, often including straightforward terms such as 'programming' and 'coding'. Very few of the wider terms and content featured in the National Curriculum Computing document were included in any of the annotation and images that may have suggested these were placed very low in the hierarchy or not featured. These omissions are the terms most associated with current 'measures' of the English computing education through Ofsted and government-led computing curriculum rhetoric. What was clearly apparent, however, was the rejection of 'ICT' both as a curriculum subject and in the wider context. Only one image displayed use of a mobile device and there is a clear dislike for traditional ICT-type tasks such as the annotated database shown in Figure 7.

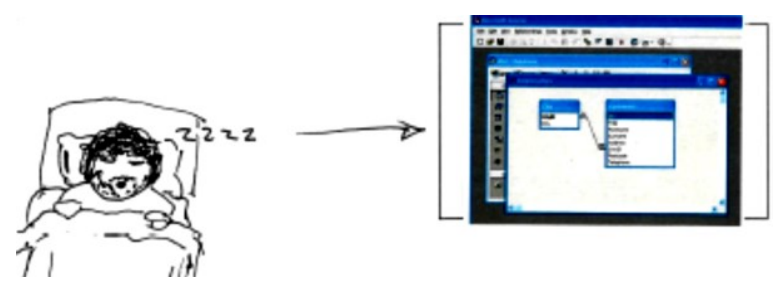

Figure 7: Database structure with student annotation

The student teachers were also asked to note any omissions they felt they were unable to represent from the images with which they were provided. Not all felt the need to take this opportunity; however, some were listed: cross curricular, inclusion, marking, differentiation, behaviour, class discussions and the internet. It is interesting how this list features some of the more challenging aspects of teaching and yet none of the images have been annotated in a way to suggest they have been 'read' as a negative feature of teaching as a profession. This is due to the nature of the study with student 
teachers being asked to prioritise and look at importance. This suggests the process may lend itself to being used in different ways, for example, specifically addressing curriculum design or teacher challenges.

One of the most revealing aspects of this research process was the participant response. The trainee teachers fully engaged with the process and were fascinated by the outcome, both their own and those of others. Following the task they requested to look at each other's work and discussed and justified their own decision making process. It also allowed university-based teacher educators to have a greater understanding of the student teacher identity and support areas they felt may be worth further discussion and exploration.

By only recording the final annotated diamonds for this study, much rich data was lost. Recording the discussions the trainees were having during the process would have provided additional insight into the process and the actual awakening of teacher identity occurring within the group. With the second cohort the student teachers were asked to volunteer to record their discussions. Only one pair did and after a short while asked if they could stop the recording. They felt their discussions were less honest and free flowing as they were conscious that university staff may listen to what they said. It may be more appropriate for student teachers to develop their own personal reflections following the discussion to contribute towards the understanding of the process. Also revisiting this activity at a later date would add another insight into identity development amongst the student teachers. What is most important is that student teachers have the opportunity to construct and re-construct their identity as part of their teacher training programme [15].

\section{Conclusion}

A main finding from the Diamond $9 \mathrm{~s}$ is the lack of priority given to subject specific topics or classroom activity. Student teachers are clearly more engaged in the 'how' of their teaching rather than the 'what'. Maybe this is where student teachers feel they have the most freedom and ability to develop their own practice, whereas the computing curriculum is a given. Conflicts between personal identity and the mandated curriculum can really hamper teacher development, a sense of achievement and so job satisfaction [4]. In the new field of computing education in English high schools, it is important any conflicts are explored, particularly to ensure the growing number of specialist teachers are able to contribute their ideas and beliefs to the development of the curriculum and to ensure retention of this new group of teachers. It is essential time is given to this within computing teacher training programmes and student teachers are able to explore where they may have ownership and influence in curriculum development in schools.

What is clear is the images have been a valuable stimulus for discussion. A move to images has ensured the student teachers have been able to have jargon-free, open discussions and really explore the aspects of teaching they most resonate with rather than paying lip service to computing curriculum rhetoric or the assessed requirements of the course. In this study the images have been collected and issued to the students. Expanding the process to encourage student teachers to take their own images, through a photo journal, may encourage them to 'look' at their teaching practice from a different 
perspective. This way the process would develop to be more personally reflective and explore identity over a period of time.

The process embraced within this paper, whilst at an early stage of development, is already appreciated by student teachers and student teacher educators. The process of engaging with the images has allowed a space for discussion and exploration which may otherwise be missed. It is important, particularly in the developing area of training computing teachers, that identity continues to be explored.

\section{References}

1. Britzman, D: Practice makes Practice. A critical study of learning to teach. (2003) New York: State University of New York Press.

2. Barthes R: Image Music Text. (1977) Fontana Press, London

3. Clark, J: Using diamond ranking as visual cues to engage young people in the research process (2012) Qualitative Research Journal, Vol. 12 Iss: 2 pp. 222 - 237

4. Connelly F M, Clandinin D J: Shaping a professional identity; stories of educational practice (1999) Teachers College Press, New York

5. Department For Education (DFE,a): Initial teacher training: trainee number census - 2014 to 2015 (2015) https://www.gov.uk/government/statistics/initial-teacher-training-traineenumber-census-2014-to-2015 Accessed 23/2/16, 14:50

6. Department For Education (DFE,b): National Curriculum from September 2014. (2013) https://www.gov.uk/government/collections/national-curriculum Accessed 14/3/14, 13:25

7. Foucault M: This is not a pipe (1983) University of California Press, Berkeley

8. Luehamnn A L: Identity Development as a Lens to Science Teacher Preparation. (2007) Wiley InterScience DOI 10.1002/sce.20209

9. Libow Martinez, S and Stager, G: Invent to Learn: Making, tinkering and engineering in the classroom. (2013) Constructing Modern Knowledge Press. Torrance, CA, USA

10. Livsey R C, Palmer P J: The courage to teach: A guide to reflection and renewal (1999) Jossey-Bass, California

11. Manghani, S, Piper \& Simons J: Images: A Reader. (2006) Sage Publications, London.

12. Ni, L and Guzdial: M Who AM I? Understanding High School Computer Science Teachers' Professional Identity. (2012) SIGCSE '12, Feb 29-March 3 2012, Raleigh, NC, USA

13. O'Kane, C: The development of participatory techniques: facilitating children's views about decisions which affect them (2000), in Christensen, P. and James, A. (Eds), Research With Children: Perspectives and Practices, Falmer Press, London, in Clark, J (2012),"Using diamond ranking as visual cues to engage young people in the research process", Qualitative Research Journal, Vol. 12 Iss: 2 pp. $222-237$

14. Royal Society: Shut Down or Retstart? The way forward for computing in UK Schools, (2012) The Royal Society, London, UK

15. Trent J: Teacher education as identity construction: insights from action research. (2010) Journal Of Education for Teaching, Vol 36, No 2, pp 153-168

16. Walkerdine V: School Girl Fictions. (1990) Verso. London

17. White, B E, Lemieux A: Reflecting Selves: Pre-Service Teacher Identity Development explored through material culture. (2015) Learning Landscapes, Vol 9, No 1, pp 267-283

18. https://drive.google.com/drive/folders/0B0iqB-MoHnQ MENQMkZyazNJWUk online copy of all images used within the study. 